\title{
Author Correction: Green Approach Towards Synthesis and Characterization of GMO/Chitosan Nanoparticles for In Vitro Release of Quercetin: Isolated from Peels of Pomegranate Fruit
}

\author{
Poournima Patil $^{1} \cdot$ Suresh Killedar ${ }^{2}$
}

Published online: 26 April 2021

๑) Springer Science+Business Media, LLC, part of Springer Nature 2021

Author Correction: Journal of Pharmaceutical Innovation https://doi.org/10.1007/s12247-021-09552-7

The original version of this article unfortunately contained a mistake in Fig. 4. Originally, Fig. 4 is identical to Fig. 9. The correct Fig. 4 is shown here.

The original article has been corrected.

The original article can be found online at https://doi.org/10.1007/ s12247-021-09552-7.

Poournima Patil poournima6@gmail.com

$\triangle$ Suresh Killedar sureshgk_64@rediffmail.com

1 Department of Pharmaceutical Chemistry, Bharati Vidyapeeth College of Pharmacy, Maharashtra, Kolhapur, India

2 Department of Pharmacognosy, Shree Sant Gajanan Maharaj College of Pharmacy, Mahagaon, Gadhinglaj, Maharashtra, India 


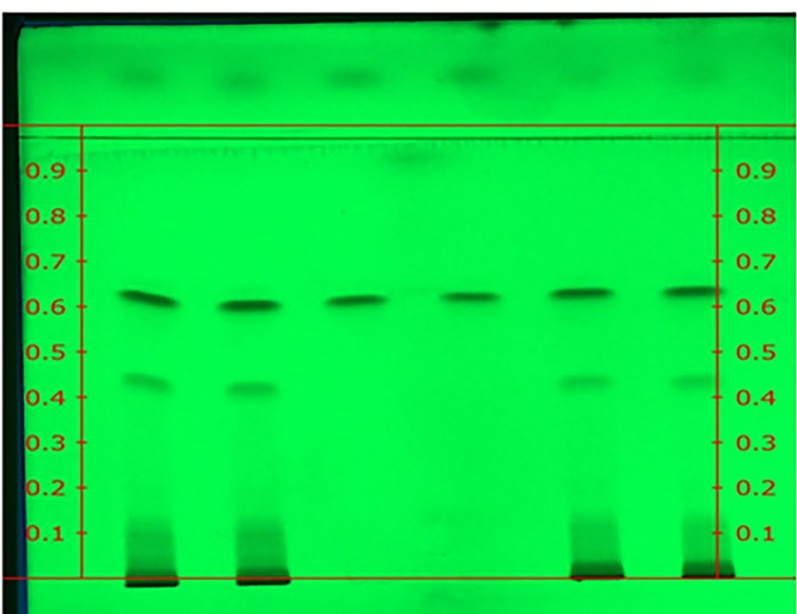

A

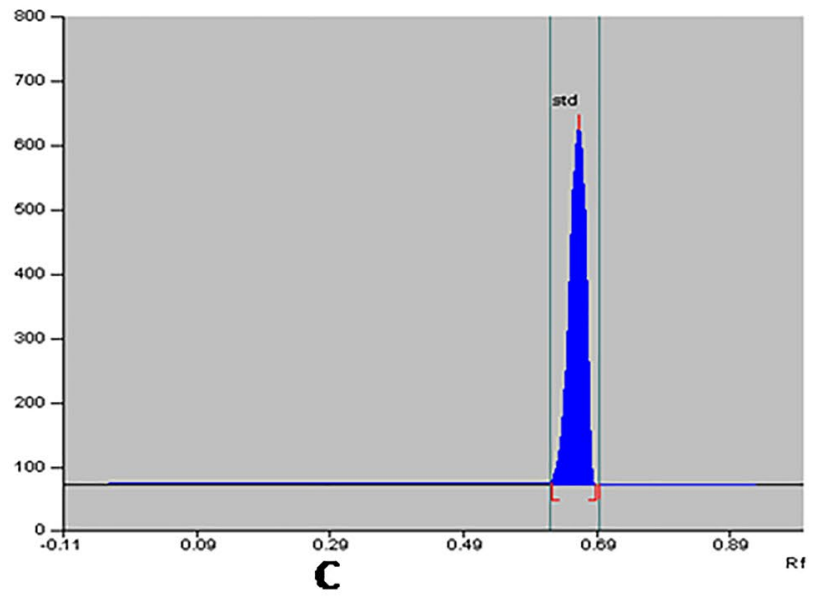

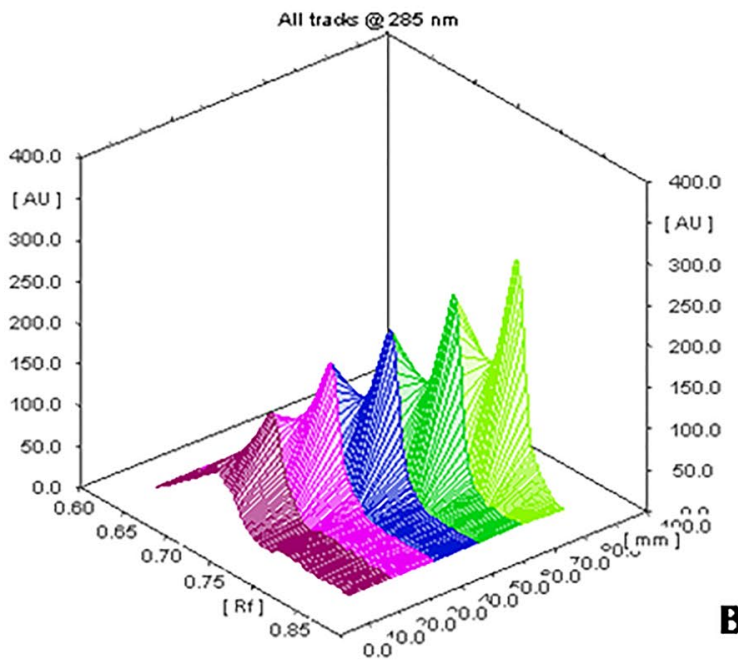

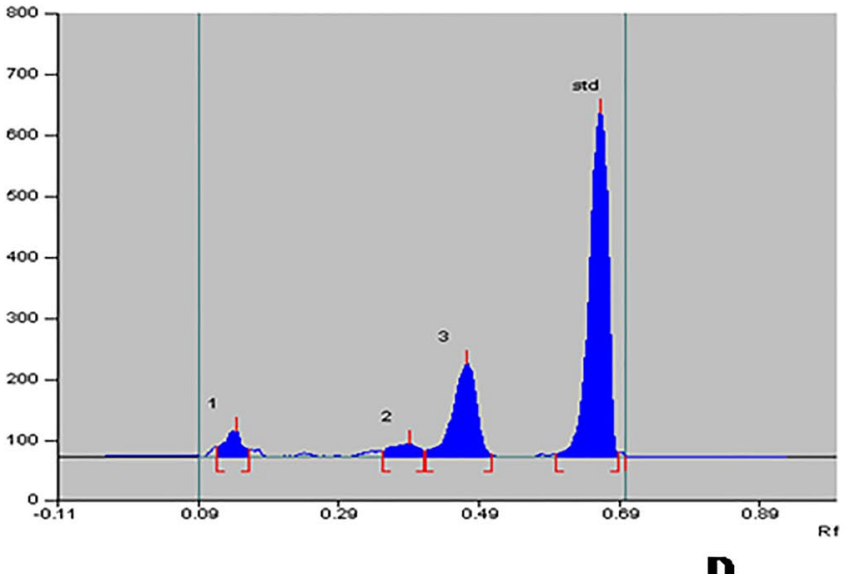

D

Fig. 4 HPTLC profile of peels of pomegranate extracts. a Fingerprinting profile. b 3D display at $285 \mathrm{~nm}$. c Chromatogram of standard quercetin. d Chromatogram of extract

Publisher's Note Springer Nature remains neutral with regard to jurisdictional claims in published maps and institutional affiliations. 